\title{
Risk factors for osteoporosis in patients with end-stage liver disease
}

\author{
SHINJIRO UCHIDA, HISAMITSU MIYAAKI, TATSUKI ICHIKAWA, \\ NAOTA TAURA, SATOSHI MIUMA, TAKUYA HONDA, HIDETAKA SHIBATA, \\ MASAFUMI HARAGUCHI, TAKEMASA SENOO and KAZUHIKO NAKAO \\ Department of Gastroenterology and Hepatology, Nagasaki University Graduate \\ School of Biomedical Sciences, Nagasaki 852-8501, Japan
}

Received May 30, 2016; Accepted September 1, 2016

DOI: $10.3892 /$ br.2016.764

\begin{abstract}
Patients with end-stage liver disease (ESLD) were evaluated and their clinical features were compared with the aim of identifying risk factors for osteoporosis. Seventy-nine patients with ESLD were enrolled in the current study. Bone mineral density (BMD) was assessed by dual-energy X-ray absorptiometry and compared with clinical features in patients with ESLD. BMD was identified to be significantly correlated with body mass index $(\mathrm{r}=0.430 ; \mathrm{P}=0.001)$ and inversely correlated with total bile acid $(\mathrm{r}=-0.228 ; \mathrm{P}=0.049)$ and urine $\mathrm{N}$-telopeptide type I collagen/creatinine ratio $(r=-0.280 ; \mathrm{P}=0.024)$. Patients with osteoporosis were significantly older (osteoporosis vs. no osteoporosis, 63.0 vs. 56.0 years; $\mathrm{P}<0.05$ ) and had higher values for total bile acid (osteoporosis vs. no osteoporosis, 306.0 vs. $129.1 \mu \mathrm{mol} / \mathrm{l}$; $\mathrm{P}<0.05)$ and corrected calcium [osteoporosis vs. no osteoporosis, 9.85 (8.7-10.7) vs. 9.70 (8.8-10.6) $\mathrm{mg} / \mathrm{dl} ; \mathrm{P}<0.05]$. In multivariate analysis, age $(\beta=-0.015 \pm 0.06 ; P=0.009)$ and total bile acid $(\beta=-0.001 \pm 0.0001 ; P=0.041)$ were identified as independent factors for osteoporosis. Finally, the risk score for osteoporosis was defined as follows: Risk score $=1.78-0.001 \times$ total bile acid-(0.16 $\mathrm{x}$ age). The area under the receiver operating characteristic (ROC) curve risk score for osteoporosis is 0.778 . Thus, the risk scores calculated in the present study may be used to predict osteoporosis in patients with ESLD.
\end{abstract}

\section{Introduction}

Osteoporosis is a generalized skeletal disease characterized by increased bone resorption and decreased bone formation, and is associated with an increased risk of bone fractures. The

Correspondence to: Dr Hisamitsu Miyaaki, Department of Gastroenterology and Hepatology, Nagasaki University Graduate School of Biomedical Sciences, 1-7-1 Sakamoto, Nagasaki 852-8501, Japan

E-mail:miyaaki-hi@umin.ac.jp

Key words: osteoporosis, end-stage liver disease, bone mineral density prevalence of osteoporosis has been increasing in Japan $(1,2)$. Osteoporosis is classified as primary, secondary and idiopathic, with the term hepatic osteodystrophy first being defined in 1960 and including secondary osteoporosis (3). The prevalence of bone disease in patients with liver disease is higher than in the general population $(4,5)$, as the majority of patients with chronic liver disease exhibit multiple risk factors for osteodystrophy, such as protein-calorie malnutrition and vitamin D deficiency. Osteoporosis is common in patients with cirrhosis, biliary disease $(6,7)$ and alcoholism $(8)$. However, hepatic osteodystrophy has gained little attention, as, compared with hepatocellular carcinoma and esophageal varices, it does not significantly affect life expectancy.

Advances in medical technology have prolonged life expectancy in patients with liver diseases. Osteoporosis decreases the quality of life, as it causes an increased risk of bone fractures. Therefore, hepatic osteodystrophy is considered to be a subject of interest.

In Japan, there have been few studies on osteoporosis in patients with end-stage liver disease (ESLD). Therefore, the clinical features of osteoporosis were examined in patients with ESLD and the associated risk factors were identified.

\section{Materials and methods}

Patient characteristics. The present study included 79 patients with ESLD admitted to Nagasaki University Hospital (Nagasaki, Japan) between June 2008 and October 2012. ESLD was defined as a patient who registered as a recipient of liver transplantation at Nagasaki University. Furthermore, patients were eligible to take part if they were aged $\geq 18$ years and had ESLD. Patients who were administered medication for osteoporosis were excluded. The current study included 2 patients with Child-Pugh class A; however, these patients exhibited portal hypertension and experienced difficulties during therapy for bleeding varices. The etiology of chronic liver disease was based on clinical, analytical and radiological criteria. The current cohort included 40 males (50.6\%) with a mean age of 57.0 years (range 24-75 years). The median Child-Pugh score was 10.0 and the model for ESLD (MELD) score was 14.00. All patients provided informed consent, and the study protocol conformed to the guidelines of the 
Table I. Baseline characteristics of the patients $(n=79)$.

\begin{tabular}{|c|c|}
\hline Variables & Value \\
\hline Age, years & $57.0(24-75)$ \\
\hline \multicolumn{2}{|l|}{ Gender } \\
\hline Male n $(\%)$ & $40(50.6)$ \\
\hline Female $\mathrm{n}(\%)$ & $39(49.4)$ \\
\hline \multicolumn{2}{|l|}{ Etiology, n (\%) } \\
\hline Viral & $51(64)$ \\
\hline $\mathrm{HCV}$ & $38(47)$ \\
\hline $\mathrm{HBV}$ & $13(17)$ \\
\hline Alcohol & $10(13)$ \\
\hline $\mathrm{PBC}$ & $7(9)$ \\
\hline AIH & $4(5)$ \\
\hline PSC & $3(3)$ \\
\hline NASH & $2(3)$ \\
\hline Other & $2(3)$ \\
\hline Body mass index & 24.7 \\
\hline MELD score & 14 \\
\hline Child-Pugh score & 10 \\
\hline Diabetes, n (\%) & $33(41)$ \\
\hline $\mathrm{HCC}, \mathrm{n}(\%)$ & $35(44)$ \\
\hline Compression fracture, n (\%) & $17(21.5)$ \\
\hline Osteoporosis, n (\%) & 23/79 (29.1) \\
\hline Male, n (\%) & $7 / 40(17.5)$ \\
\hline Female, n (\%) & $16 / 39(41.0)$ \\
\hline AST (IU/l) & $37.0(12-154)$ \\
\hline ALT (IU/l) & $41.0(19-244)$ \\
\hline ALP (IU/1) & $415.0(171-1180)$ \\
\hline $\mathrm{BTR}(\mu \mathrm{mol} / \mathrm{l})$ & $3.00(1.58-7.24)$ \\
\hline ChE (IU/l) & $102.7(36-279)$ \\
\hline Total bile acid $(\mu \mathrm{mol} / \mathrm{l})$ & $145.1(7.4-639.5)$ \\
\hline Albumin (g/dl) & $2.80(1.9-4.2)$ \\
\hline T-Cho (mg/dl) & $123.0(50-331)$ \\
\hline Bone-ALP (U/1) & $24.9(7.9-44.2)$ \\
\hline Osteocalcin (ng/ml) & $5.60(1-32)$ \\
\hline Urine-NTx/CR (nmol BCE/mmol CR) & $37.3(11.3-142.4)$ \\
\hline Hemoglobin (g/dl) & $10.6(6.2-17.3)$ \\
\hline Platelet $\left(10^{4} / \mu 1\right)$ & $6.20(2.2-27.3)$ \\
\hline BMD (T-score) spine & $-1.90(-5.5-4.3)$ \\
\hline
\end{tabular}

$\mathrm{HCV}$, hepatitis $\mathrm{C}$ virus; $\mathrm{HBV}$, hepatitis $\mathrm{B}$ virus; $\mathrm{PBC}$, primary biliary cirrhosis; AIH, auto-immune hepatitis; PSC, primary sclerosing cholangitis; NASH, non-alcoholic steatohepatitis; MELD score, model for end-stage liver disease; HCC, hepatocellular carcinoma; AST, aspartate transaminase; ALT, alanine aminotransferase; ALP, alkaline phosphatase; BTR, branched chain amino acid to tyrosine ratio; $\mathrm{ChE}$, cholinesterase; T-Cho, total cholesterol; BMD, bone mineral density; $\mathrm{NTx}, \mathrm{N}$-telopeptide type I collagen; BCE, bone collagen equivalent; $\mathrm{CR}$, creatinine.

Declaration of Helsinki and was approved by the Nagasaki University Ethics Committee (approval no. 16042537). Patient characteristics are summarized in Table I.
Table II. Correlation between clinical data and bone mineral density.

\begin{tabular}{lcc}
\hline Variables & Correlation coefficient & P-value \\
\hline Age & 0.164 & 0.149 \\
Body mass index & 0.430 & 0.001 \\
MELD score & -0.019 & 0.880 \\
Child-Pugh score & -0.153 & 0.205 \\
AST & 0.051 & 0.656 \\
ALT & -0.007 & 0.954 \\
ALP & -0.082 & 0.474 \\
BTR & -0.117 & 0.327 \\
ChE & 0.160 & 0.159 \\
Total bile acid & -0.228 & 0.049 \\
Albumin & 0.128 & 0.263 \\
T-Cho & 0.048 & 0.677 \\
Hemoglobin & 0.109 & 0.337 \\
Platelet & -0.076 & 0.503 \\
Prothrombin time INR & -0.016 & 0.893
\end{tabular}

MELD score, model for end-stage liver disease; AST, aspartate transaminase; ALT, alanine aminotransferase; ALP, alkaline phosphatase; BTR, branched chain amino acid to tyrosine ratio; ChE, cholinesterase; T-Cho, total cholesterol.

Table III. Correlation between biochemical bone metabolism data and bone mineral density.

\begin{tabular}{lcc}
\hline Variables & Correlation coefficient & P-value \\
\hline Urine NTx/CR & -0.280 & 0.024 \\
BAP & 0.024 & 0.841 \\
Osteocalcin & 0.052 & 0.673 \\
Corrected calcium & -0.109 & 0.340 \\
Intact PTH & -0.127 & 0.289 \\
$1,25(\mathrm{OH}) 2$ vitamin D & 0.155 & 0.201 \\
\hline
\end{tabular}

NTx, N-telopeptide type I collagen; CR, creatinine; BAP, bone specific alkaline phosphatase; PTH, parathyroid hormone.

The following clinical items were collected at enrolment for each patient: Age, gender, body mass index (BMI), Child-Pugh score, MELD score, and treatments that could affect bone mineral density (BMD; corticosteroids, hormone replacement therapy, calcium and vitamin supplementation, and antiosteoporotic agents, taken either currently or in the last 24 months).

In addition, the results of recent blood tests (within 1 month) were collected: Serum bilirubin, alanine aminotransferase (ALT), aspartate transaminase (AST), alkaline phosphatase, $\gamma$-glutamyl transferase, platelet count, prothrombin time, albumin, total cholesterol and total bile acid.

Assessment of bone mineral density. BMD was assessed by dual-energy X-ray absorptiometry (DEXA) using a Norland 
Table IV. Clinical, biological and biochemical data in patients with and without osteoporosis.

\begin{tabular}{|c|c|c|c|}
\hline Variables & Osteoporosis $(23 / 79)$ & No osteoporosis $(56 / 79)$ & P-value \\
\hline Age (years) & $63.0(24-75)$ & $56.0(34-70)$ & $<0.05$ \\
\hline Gender (male/female) & $7 / 16$ & $33 / 23$ & $<0.05$ \\
\hline $\operatorname{BMI}\left(\mathrm{kg} / \mathrm{m}^{2}\right)$ & $23.8(18.4-30.2)$ & $25.3(18.6-37.3)$ & N.S \\
\hline MELD score & $14.5(9-29)$ & $14.0(6-34)$ & N.S \\
\hline Child-Pugh score & $10.0(6-13)$ & $9.0(6-15)$ & N.S \\
\hline Diabetes $(\%)^{\mathrm{a}}$ & 34.8 & 30.4 & N.S \\
\hline $\operatorname{HCC}(\%)^{\mathrm{a}}$ & 47.8 & 41.1 & N.S \\
\hline AST (IU/1) & $38.0(14-128)$ & $34.0(12-154)$ & N.S \\
\hline ALT (IU/1) & $35.0(1-56)$ & $44.0(9-244)$ & N.S \\
\hline ALP (IU/1) & $406.0(178-46)$ & $415.0(171-1185)$ & N.S \\
\hline $\mathrm{BTR}(\mu \mathrm{mol} / \mathrm{l})$ & $2.81(1.54-8.17)$ & $3.07(0.76-36.90)$ & N.S \\
\hline ChE (IU/l) & $94.0(36-179)$ & $91.5(33-279)$ & N.S \\
\hline Total bile acid $(\mu \mathrm{mol} / \mathrm{l})$ & $306.0(28.4-639.5)$ & $129.1(7.2-631)$ & $<0.05$ \\
\hline Albumin (g/dl) & $2.7(2.0-3.7)$ & $2.9(1.9-4.2)$ & N.S \\
\hline T-Cho (mg/dl) & $105.0(50-171)$ & $123.0(51-331)$ & N.S \\
\hline Hemoglobin (g/dl) & $10.6(7.9-14.1)$ & $10.7(6.2-17.3)$ & N.S \\
\hline Platelet $\left(10^{4} / \mu 1\right)$ & $6.4(2.1-26.3)$ & $6.0(0.2-27.3)$ & N.S \\
\hline Prothrombin time INR & $1.41(1.24-1.81)$ & $1.43(0.99-3.28)$ & N.S \\
\hline Compression fracture $(\%)$ & 60.9 & 5.4 & $<0.05$ \\
\hline
\end{tabular}

${ }^{a}$ Data analyzed by $\chi^{2}$ test. Remaining analysis was conducted using the Mann-Whitney U test. BMI, body mass index; N.S, not significant; MELD, model for end-stage liver disease; HCC, hepatocellular carcinoma; AST, aspartate transaminase; ALT, alanine aminotransferase; ALP, alkaline phosphatase; BTR, branched chain amino acid to tyrosine ratio; ChE, cholinesterase; T-Cho, total cholesterol; BMD, bone mineral density; NTx, N-telopeptide type I collagen; CR, creatinine.

XR-46 DEXA (Swissray Global Healthcare Holding Ltd., Taipei, Taiwan) scan of the lumbar spine. Norland XR-46 ${ }^{\mathrm{TM}}$ software was used to compute the BMD in $\mathrm{mg} / \mathrm{cm}^{2}$ (of calcium hydroxyapatite equivalent), aggregate the results, and compute the mean BMD and the T score. The T score was defined as the number of standard deviations from the mean BMD values of healthy young adults. Hepatic osteodystrophy was defined as the presence of osteoporosis or osteopenia; osteopenia was defined as a $\mathrm{T}$ score between -1 and -2.5 , and osteoporosis was defined as a $\mathrm{T}$ score $<-2.5$ below the reference value, or the existence of a compression fracture with osteopenia ( $\mathrm{T}$ score: World Health Organization criteria) (9).

Statistical analysis. All statistical analysis was performed with Stat-flex version 6 (Artech Co., Ltd., Osaka, Japan). The Mann-Whitney U test was used for comparisons between groups. The presence of osteoporosis in ESLD was analyzed with a $\chi^{2}$-test. Receiver operating characteristic (ROC) curves were used to determine an appropriate cut-off for the continuous variable and $\mathrm{P}<0.05$ was considered to indicate a statistically significant difference.

\section{Results}

Correlation between clinical features and bone mineral density. The T-score was significantly correlated with BMI $(\mathrm{r}=0.430 ; \mathrm{P}=0.001)$ and inversely correlated with total bile acid $(\mathrm{r}=-0.228 ; \mathrm{P}=0.049$; Table II). A significant correlation between the T-score and biochemical bone metabolism factors was only identified for the urine $\mathrm{N}$-telopeptide type I collagen $(\mathrm{NTx}) /$ creatinine $(\mathrm{CR})$ ratio $(\mathrm{r}=-0.280 ; \mathrm{P}=0.024$; Table III).

Clinical features in patients with and without osteoporosis. Osteoporosis was observed in 23 of 79 (29\%) patients. Patients with osteoporosis were significantly older (osteoporosis vs. no osteoporosis: 63.0 (24-75) vs. 56.0 (34-70) years; $\mathrm{P}<0.05)$, had higher total bile acid (osteoporosis vs. no osteoporosis: 306.0 (28.4-639.5) vs. 129.1 (7.2-631) $\mu \mathrm{mol} / \mathrm{l} ; \mathrm{P}<0.05)$ (Table IV) and higher corrected calcium [osteoporosis vs. no osteoporosis: 9.85 (8.7-10.7) vs. 9.70 (8.8-10.6) mg/dl ; P<0.05] (Table V).

An increased number of females had osteoporosis (osteoporosis vs. no osteoporosis, 69 vs. 41\%; $\mathrm{P}<0.05$ ) and the prevalence of bone fractures was significantly higher in patients with osteoporosis. Prevalence of osteoporosis tended to be higher in cholestatic disease than in non-cholestatic disease, although the difference was not significant $[4 / 10$ (40\%) vs. $19 / 69$ (27.5\%); $\mathrm{P}=0.07]$. Among the biochemical bone metabolism markers, only corrected calcium was significantly higher in patients with osteoporosis. In multivariate analysis, age $(\beta=-0.015 \pm 0.06 ; P=0.009)$ and total bile acid ( $\beta=-0.001 \pm 0.0001 ; \mathrm{P}=0.041)$ were independent risk factors for osteoporosis (Table VI).

Among patients with hepatitis $\mathrm{C}$ virus, those with osteoporosis were also significantly older [osteoporosis vs. no osteoporosis: 60.7 (52-72) vs. 55.5 years (43-70); $\mathrm{P}<0.05]$ (Table VII). They were more likely to be female (male 
Table V. Biochemical bone metabolism data in patients with and without osteoporosis.

\begin{tabular}{lccc}
\hline Variables & Osteoporosis $(23 / 79)$ & No osteoporosis $(56 / 79)$ & P-value \\
\hline Urine NTx CR (nmol BCE/mmol CR) & $47.2(15.1-152.4)$ & $35.6(11.3-98.3)$ & N.S \\
BAP $(\mu \mathrm{g} / \mathrm{l})$ & $25.3(7.9-42.7)$ & $24.5(11.8-91.0)$ & N.S \\
Osteocalcin $(\mathrm{ng} / \mathrm{ml})$ & $5.6(1-14)$ & $5.6(1-32)$ & N.S \\
Corrected calcium $(\mathrm{mg} / \mathrm{dl})$ & $9.85(8.7-10.7)$ & $9.70(8.8-10.6)$ & $<0.05$ \\
Intact PTH $(\mathrm{pg} / \mathrm{dl})$ & $29.0(14.0-93.0)$ & $26.0(7.0-90.0)$ & N.S \\
$1,25(\mathrm{OH}) 2$ vitamin D $(\mathrm{pg} / \mathrm{ml})$ & $37.4(16.0-67.0)$ & $36.9(10.4-89.5)$ & N.S
\end{tabular}

NTx, N-telopeptide type I collagen; BCE, bone collagen equivalent; CR, creatinine; N.S, not significant; BAP, bone specific alkaline phosphatase; $\mathrm{PTH}$, parathyroid hormone.

Table VI. Independent risk factors for osteoporosis in patients with end stage liver disease.

\begin{tabular}{lcc}
\hline Variables & P-value & $\beta$ \\
\hline Gender & 0.362 & $0.096 \pm 0.105$ \\
Age & 0.009 & $-0.015 \pm 0.006$ \\
Total bile acid & 0.041 & $-0.001 \pm 0.0001$ \\
Corrected calcium & 0.116 & $-0.199 \pm 0.125$ \\
\hline
\end{tabular}

Table VII. Clinical data in HCV patients with and without osteoporosis $(n=38)$.

\begin{tabular}{lccc}
\hline Variables & $\begin{array}{c}\text { Osteoporosis } \\
(\mathrm{n}=13)\end{array}$ & $\begin{array}{c}\text { No osteoporosis } \\
(\mathrm{n}=25)\end{array}$ & P-value \\
\hline Age & $60.7(52-72)$ & $55.5(43-70)$ & $<0.05$ \\
$\begin{array}{l}\text { Gender } \\
\text { M/f }\end{array}$ & $4 / 9$ & $17 / 8$ & $<0.05$ \\
$\begin{array}{l}\text { Total bile } \\
\text { acid }\end{array}$ & $321.1(41.2-639.5)$ & $200.8(17.1-631)$ & $<0.05$ \\
\hline
\end{tabular}

aata analyzed by $\chi^{2}$ test. Remaining analysis was conducted using the Mann-Whitney U test. M, male; f, female.

Table VIII. Clinical data in cholestatic disease patients with and without osteoporosis $(\mathrm{n}=10)$.

\begin{tabular}{lccc}
\hline Variables & $\begin{array}{c}\text { Osteoporosis } \\
(\mathrm{n}=4)\end{array}$ & $\begin{array}{c}\text { No osteoporosis } \\
(\mathrm{n}=6)\end{array}$ & P-value \\
\hline $\begin{array}{l}\text { Age } \\
\text { Gender }\end{array}$ & $52.5(24-65)$ & $57.6(43-70)$ & N.S \\
$\begin{array}{l}\text { M/f } \\
\text { Total bile }\end{array}$ & $305.7(147.5-387.1)$ & $123.2(67.3-212.2)$ & $<0.05$ \\
acid & $0 / 4$ & $2 / 4$ & \\
\hline
\end{tabular}

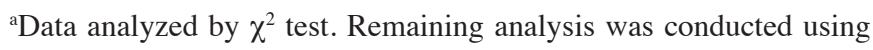
the Mann-Whitney U test. M, male; f, female. vs. female: 69 vs. $32 \%$; $\mathrm{P}<0.05)$ and had higher total bile acid levels [osteoporosis vs. no osteoporosis: 306.0 (28.4-639.5) vs. 129.1 (7.2-631) $\mu \mathrm{mol} / \mathrm{l} ; \mathrm{P}<0.05]$. Among patients with cholestatic disease, those with osteoporosis had higher total bile acid levels [osteoporosis vs. no osteoporosis: 305.7 (147.5-387.1) vs. 123.2 (67.3-212.2) $\mu \mathrm{mol} / \mathrm{l} ; \mathrm{P}<0.05]$ (Table VIII).

Risk score for osteoporosis. The risk score for osteoporosis was defined based on multivariate analysis as follows: Risk score $=1.78-0.001 \times$ total bile acid $-(0.16 \mathrm{x}$ age $)$. The area under the ROC curve was 0.778 .

\section{Discussion}

The present study revealed that BMD was significantly correlated with BMI and total bile acid. Previous studies reported that a low BMI and malnutrition were risk factors for osteoporosis and bone fractures $(10,11)$. Low BMI was associated with malnutrition; therefore, in patients with ESLD, malnutrition was considered to be a factor as important as osteodystrophy.

The elevation of total bile acid is associated with the impairment of enterohepatic circulation (12). In the current study, total bile acid showed an inverse correlation with BMD in patients with ESLD. A significant difference between patients with and without osteoporosis was also found for total bile acid. In addition, significant differences were identified in total bile acid levels in patients with chronic hepatitis $\mathrm{C}$ and cholestatic disease. The mechanism is as follows: The impairment of bile acid secretion in the intestine decreases the formation of lipid soluble vitamins, including vitamin D $(13,14)$. The activated vitamin D regulates calcium absorption and BMD. Furthermore, previous reports have shown that bile duct ligated rats had severe cholestasis, but developed low turnover osteoporosis (15).

Among biochemical bone metabolism markers, only urine NTx/CR was significantly negatively correlated with BMD. Among bone resorption markers, urine NTx/CR is the most frequently used in clinical practice (16). This biochemical bone metabolism marker changes prior to alterations in BMD. Therefore, urine NTx/CR may be an effective marker of BMD in patients with ESLD. However, osteogenic markers, such as osteocalcin and bone specific alkaline phosphatase were not correlated with BMD. This indicated that bone resorption was greater in patients with ESLD. 
In the present study, the prevalence of osteoporosis was $29 \%$ (17.5\% in males and $41.0 \%$ in females). According to the Japanese Society for Bone and Mineral Research, the prevalence of osteoporosis in the Japanese general population is $4 \%$ in males and 24\% in females (17). Therefore, ESLD is a major risk factor for osteoporosis. The observed prevalence in patients with ESLD was consistent with previous reports (18-20).

Previous studies have reported that cholestatic liver disease, including primary biliary cirrhosis and primary sclerosing cholangitis are risk factors for osteoporosis (21-23). However, in the current study, the prevalence of osteoporosis tended to be higher in cholestatic disease than in non-cholestatic disease, although there was no significant difference identified. The reason for this is that the study did not include non-cirrhotic disease. The majority of patients with ESLD have a certain level of cholestasis. The current study demonstrated that cholestasis is a major risk factor for osteoporosis.

Significant differences between patients with and without osteoporosis were observed for age, female gender and total bile acid. Upon multivariate analysis, age and total bile acid were identified as risk factors for osteoporosis and predictive scores for osteoporosis were devised for patients with ESLD. If the score is $\leq 0.174$, sensitivity is 0.815 and specificity is 0.62 , patients require DEXA and treatment.

There were certain limitations of the present study. This was a retrospective study from a single hospital and had a small sample size. In future, a study of patients with ESLD from multiple centers is required to validate the current results.

In conclusion, age and total bile acid were identified as significant predictors of osteoporosis in patients with ESLD. In addition, the risk score calculated by multivariate analysis may be a useful marker for the prediction of osteoporosis in patients with ESLD.

\section{References}

1. Yoshimura N, Muraki S, Oka H, Kawaguchi H, Nakamura K and Akune T: Cohort profile: Research on osteoarthritis/osteoporosis against disability Study. Int J Epidemiol 39: 988-995, 2010.

2. Yoshimura N, Muraki S, Oka H, Mabuchi A, En-Yo Y, Yoshida M, Saika A, Yoshida H, Suzuki T, Yamamoto S, et al: Prevalence of knee osteoarthritis, lumbar spondylosis, and osteoporosis in Japanese men and women: The research on osteoarthritis/osteoporosis against disability study. J Bone Miner Metab 27: 620-628, 2009.

3. Goel V and Kar P: Hepatic osteodystrophy. Trop Gastroenterol 31: $82-86,2010$

4. Bonkovsky HL, Hawkins M, Steinberg K, Hersh T, Galambos JT, Henderson JM, Millikan WJ and Galloway JR: Prevalence and prediction of osteopenia in chronic liver disease. Hepatology 12 273-280, 1990.

5. Goral V, Simsek M and Mete N: Hepatic osteodystrophy and liver cirrhosis. World J Gastroenterol 16: 1639-1643, 2010.
6. Herlong HF, Recker RR and Maddrey WC: Bone disease in primary biliary cirrhosis: Histologic features and response to 25-hydroxyvitamin D. Gastroenterology 83: 103-108, 1982.

7. Parés A and Guañabens N: Oste-oporosis in primary biliary cirrhosis: Pathogenesis and treatment. Clin Liver Dis 12 407-424, 2008

8. Peris P, Guañabens N, Parés A, Pons F, del Rio L, Monegal A, Surís X, Caballería J, Rodés J and Muñoz-Gómez J: Vertebral fractures and osteopenia in chronic alcoholic patients. Calcif Tissue Int 57: 111-114, 1995.

9. No authors listed: Assessment of fracture risk and its application to screening for postmenopausal osteoporosis. Report of a WHO Study Group. World Health Organ Tech Rep Ser 843: 1-129, 1994.

10. Mounach A, Ouzzif Z, Wariaghli G, Achemlal L, Benbaghdadi I, Aouragh A, Bezza A and El Maghraoui A: Primary biliary cirrhosis and osteoporosis: A case-control study. J Bone Miner Metab 26: 379-384, 2008.

11. Santolaria F, González-Reimers E, Pérez-Manzano JL, Milena A, Gómez-Rodríguez MA, González-Díaz A, de la Vega MJ and Martínez-Riera A: Osteopenia assessed by body composition analysis is related to malnutrition in alcoholic patients. Alcohol 22: 147-157, 2000.

12. Hofmann AF: The enterohepatic circulation of bile acids in man. In: The Hepatobiliary System. Taylor W (ed). Springer Science and Business Media, NY, pp517-527, 1976.

13. Kitson MT and Roberts SK: D-livering the message: The importance of vitamin D status in chronic liver disease. J Hepatol 57: 897-909, 2012.

14. Tsiaras WG and Weinstock MA: Factors influencing vitamin D status. Acta Derm Venereol 91: 115-124, 2011.

15. Ackerman Z, Weinreb M, Amir G and Pollak RD: Bone mineral metabolism and histomorphometry in rats with cholestatic liver disease. Liver 22: 166-172, 2002.

16. Delmas PD, Eastell R, Garnero P, Seibel MJ and Stepan J; Committee of Scientific Advisors of the International Osteoporosis Foundation: The use of biochemical markers of bone turnover in osteoporosis. Osteoporos Int 11 (Suppl 6): S2-S17, 2000

17. Sone T and Fukunaga M: Prevalence of osteoporosis in Japan and the international comparison. Nihon Rinsho 62 (Suppl 2): 197-200, 2004 (In Japanese).

18. Sokhi RP, Anantharaju A, Kondaveeti R, Creech SD, Islam KK and Van Thiel DH: Bone mineral density among cirrhotic patients awaiting liver transplantation. Liver Transpl 10: 648-653, 2004.

19. Ninkovic M, Skingle SJ, Bearcroft PW, Bishop N, Alexander GJ and Compston JE: Incidence of vertebral fractures in the first three months after orthotopic liver transplantation. Eur J Gastroenterol Hepatol 12: 931-935, 2000.

20. Monegal A, Navasa M, Guañabens N, Peris P, Pons F, Martinez de Osaba MJ, Rimola A, Rodés J and Muñoz-Gómez J: Osteoporosis and bone mineral metabolism disorders in cirrhotic patients referred for orthotopic liver transplantation. Calcif Tissue Int 60: 148-154, 1997.

21. Guañabens N, Parés A, Ros I, Caballería L, Pons F, Vidal S, Monegal A, Peris P and Rodés J: Severity of cholestasis and advanced histological stage but not menopausal status are the major risk factors for osteoporosis in primary biliary cirrhosis. J Hepatol 42: 573-577, 2005.

22. Leslie WD, Bernstein CN and Leboff MS; American Gastroenterological Association Clinical Practice Commitee: AGA technical review on osteoporosis in hepatic disorders. Gastroenterology 125: 941-966, 2003.

23. Angulo P, Therneau TM, Jorgensen A, DeSotel CK, Egan KS, Dickson ER, Hay JE and Lindor KD: Bone disease in patients with primary sclerosing cholangitis: Prevalence, severity and prediction of progression. J Hepatol 29: 729-735, 1998. 